\title{
Recurrent Acute Lymphoblastic Leukemia
}

National Cancer Institute

\section{Source}

National Cancer Institute. Recurrent Acute Lymphoblastic Leukemia. NCI Thesaurus.

Code C142810.

The reemergence of acute lymphoblastic leukemia after a period of remission. 